\title{
Microstructural Analysis of Additively Manufactured 304L Stainless Steel Oxide Dispersion Strengthened Alloy
}

\author{
Milad Ghayoor ${ }^{1,3}$, Kijoon Lee ${ }^{1,3}$, Yujuan $\mathrm{He}^{2}$, Chih-hung Chang ${ }^{2}$, Brian K. Paul ${ }^{1,3}$ and Somayeh \\ Pasebani ${ }^{1,3 *}$ \\ 1. School of Mechanical, Industrial and Manufacturing Engineering (MIME), Oregon State University, \\ Corvallis, OR, USA. \\ 2. School of Chemical, Biological and Environmental Engineering (CBE), Oregon State University, \\ Corvallis, OR, USA. \\ 3. Advanced Technology and Advanced Manufacturing Institute (ATAMI), Corvallis, OR, USA. \\ * Corresponding author: Somayeh.pasebani@oregonstate.edu
}

Selective laser melting (SLM) is one of the additive manufacturing (AM) process that utilizes laser for selectively melting and fusing of a thin layer of powder. This technique allows manufacturing a part directly from computer-aided design (CAD) models by dividing the part into a set of two-dimensional slices, which are built sequentially on top of another. SLM technology enables manufacturing of complex geometries, such as parts with inner cooling channels which could be difficult or time consuming to make by conventional manufacturing processes $[1,2]$.

Oxide dispersion strengthened (ODS) alloys are type of alloys consisting of a high number density ( $\left.10^{24} \mathrm{~m}^{-2}\right)$ of small $(5-50 \mathrm{~nm})$ oxide particles such as alumina $\left(\mathrm{Al}_{2} \mathrm{O}_{3}\right)$ or Yttria $\left(\mathrm{Y}_{2} \mathrm{O}_{3}\right)$ dispersed within a metallic matrix (e.g. Fe, Ni). Conventional manufacturing of ODS alloy includes numerous steps such as mechanical alloying (MA) and hot consolidation making its manufacturing costly, time-consuming and inconsistent [3]. 304L austenitic stainless steel is a structural alloy with good mechanical properties at room temperature, good corrosion, and oxidation resistance. However, application of 304L in high temperature is limited due to inferior mechanical properties at elevated temperatures [4]. Objective of this study was to utilize slight ball milling and SLM to consolidate numerous manufacturing steps into one step. Furthermore, to enhance high-temperature microstructural stability and mechanical properties of 304L through an oxide dispersion mechanism, nanoparticles of Yttria $\left(\mathrm{Y}_{2} \mathrm{O}_{3}\right)$ were dispersed within 304L matrix. The application of ODS alloy will be in energy (nuclear and coal power) and at severe environments such as at elevated temperatures.

In this work, the feedstock powder was prepared by mixing Sandvik's gas-atomized spherical 304L stainless steel powder $(<45 \mu \mathrm{m})$ with $5 \mathrm{wt} . \%$ of irregular shaped Yttria powder $(<1 \mu \mathrm{m})$ in a planetary ball mill for 4 hours with a ball-to-powder ratio of 5:1 within a nitrogen atmosphere. The specimen was manufactured using OR Creator SLM machine with optimized parameters. The as-fabricated sample was cross-sectioned and electroetched. The FEI Helios 650 scanning electron microscopy and focused ion beam (SEM/FIB), and FEI TITAN 80-200 transmission electron microscopy (TEM) equipped with ChemiSTEM technology were used to characterize the microstructure of SLMed ODS 304L alloy.

Figure 1a, the SEM micrograph of SLMed ODS 304L alloy, shows the typical cellular microstructure of the SLM process which forms due to rapid solidification. The size of this cellular structure was varied in different regions with the majority less than $1 \mu \mathrm{m}$. Figure $1 \mathrm{~b}$ reveals the precipitation of very fine and spherical nanoparticles in the range of 20-80 nm. Formation of spherical nanoparticles implied that Yttria particles mixed with 304L were melted during SLM and precipitated within the matrix during 
cooling stage. Furthermore, Figure 2 presents the high-angle annular dark-field (HAADF) image and the corresponding energy dispersive X-ray spectroscopy (EDS) maps. According to the EDS analysis, the nanoparticles were a compound of yttrium, silicon, and oxygen with higher stability compared to Yttria. Microhardness test was used to evaluate properties of SLMed 304L and ODS alloy. Adding 5 wt.\% of

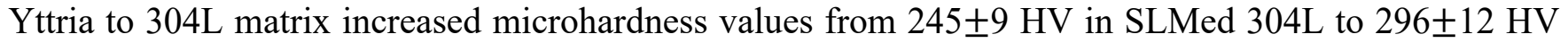
in SLMed 304L+5 wt.\% $\mathrm{Y}_{2} \mathrm{O}_{3}$. This preliminary study demonstrated SLM additive manufacturing process as a promising alternative to conventional routes in manufacturing of ODS alloys [5].

\section{References:}

[1] S Pasebani et al. Additive Manufacturing, 22 (2018), p. 127.

[2] M Ghayoor et al., Materials Science Forum, 941 (2018), p. 698.

[3] GR Odette, MJ. Alinger and BD. Wirth, Annual Review: Material Research, 38 (2008), p. 471.

[4] Y Miao et al. Materials Science and Engineering: A, 625 (2015), p. 146.

[5] The authors would like to acknowledge the funding of critical equipment provided by the Murdock Charitable Trust (Contract number: 2016231:MNL:5/18/2017), the RAPID Institute and U.S. DOE for financial support. The authors also thank OSU electron microscopy center and ATAMI facility staff and director.
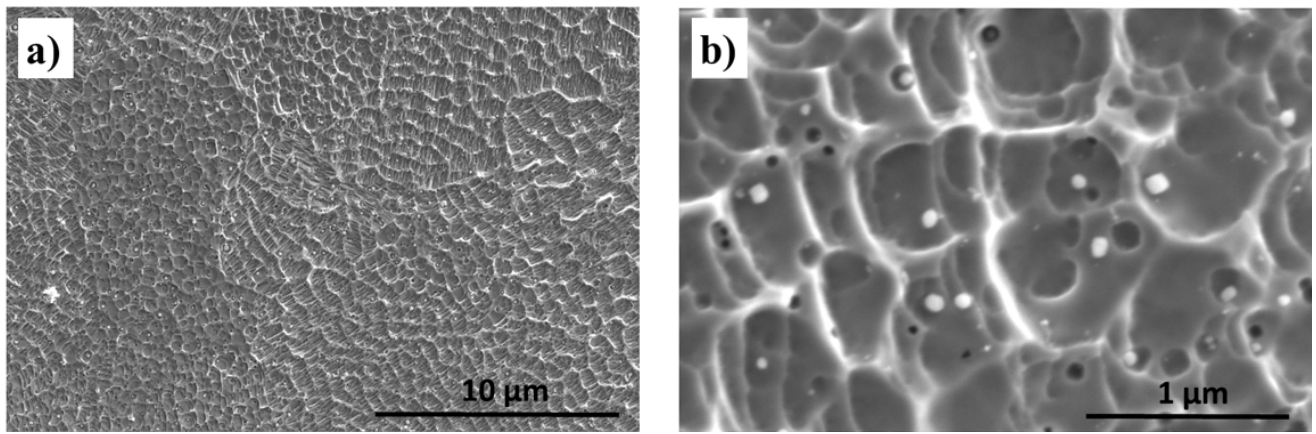

Figure 1. SEM micrograph of 304L SS ODS alloy a) Typical cellular substructure of SLM process

b) Precipitation of spherical nanoparticles within the 304 matrix
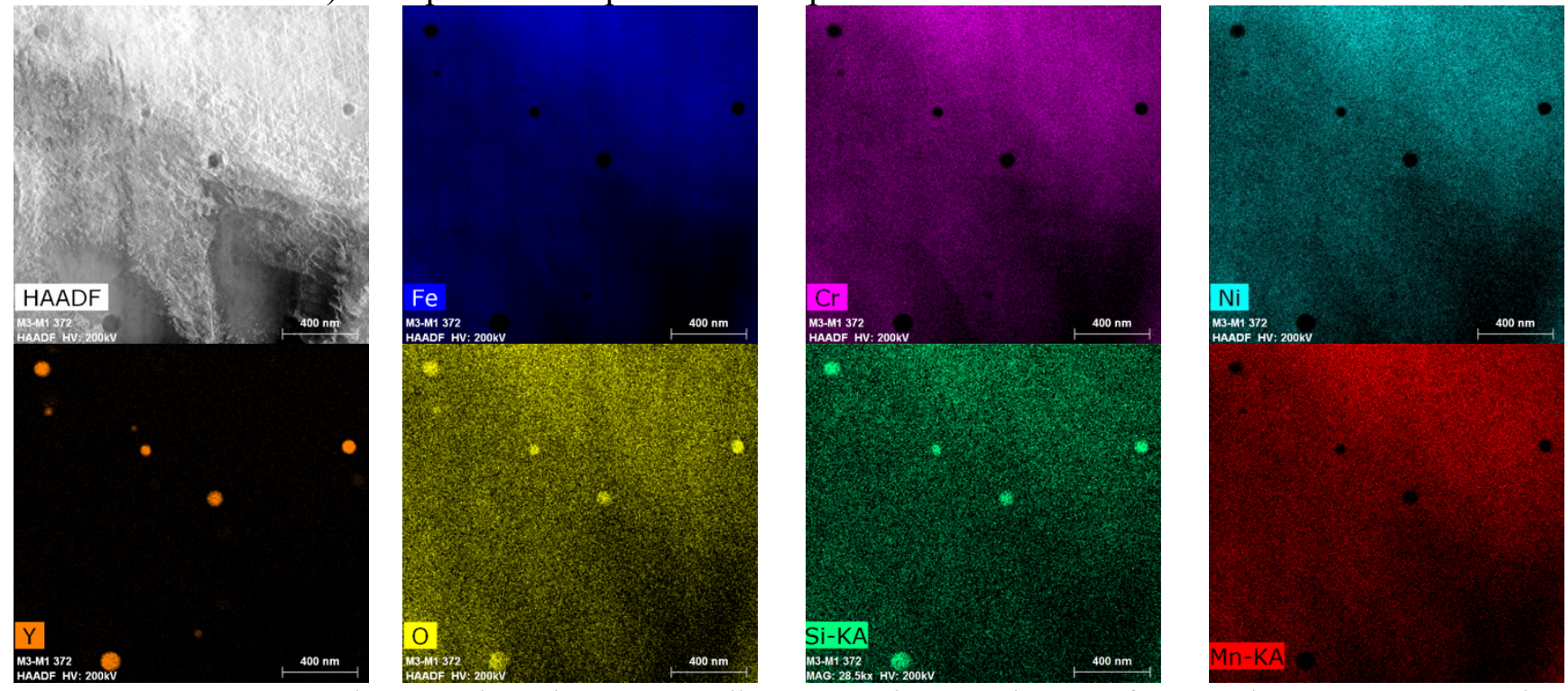

Figure 2. HAADF micrograph and corresponding EDS elemental map of SLMed 304+5 wt.\% Yttria, identifying the nanoparticles as a compound of yttrium, silicon, and oxygen 